Yuval Leonov $^{1}$, Igor Kisil', Alona Perlov ${ }^{1 *}$, Vladimir Stoichev', Yulia Ginzburg ${ }^{1 *}$, Alla Nazarenko ${ }^{1}$, Yuri Gimelfarb ${ }^{2}$

'Bayit Balev Geriatric and Rehabilitation Center, Maccabi Health Services, Bat Yam, Israel

${ }^{2}$ AMHC, Bat Yam, affiliated to the Sackler Faculty of Medicine, Tel Aviv University, Israel

${ }^{*}$ At the time of research

\title{
Predictors of successful weaning in patients requiring extremely prolonged mechanical ventilation
}

\begin{abstract}
Introduction: For patients on prolonged mechanical ventilation (PMV; > 21 days), successful weaning has been attributed to various factors. The aim of this study is to determine the usefulness of the rapid shallow breathing index (RSBI) and other potential predictors of successful weaning in patients unable to wean and requiring extreme PMV at a hospital-based long-term ventilator facility in Israel.

Material and ethods: Retrospective analysis of prospectively collected data over 5 years.

Results: A total of 150 subjects on PMV, ready to undergo a weaning process, were included in the study. Of them, 60 (40.0\%) were males. The mean age of the whole study population was 76.5 years ( $S D=13.6$; range 22.0-96.0 years). The subjects were on MV for a mean period of 170.1 days (SD = 237.6; range 25.0-1624.0 days). Sixty patients (40\%) were successfully weaned. The mean RSBI in the successfully weaned population was 41.9 breaths $/ \mathrm{min} / \mathrm{L}$ (SD = 12.3; range 13.0-80.4 breaths $/ \mathrm{min} / \mathrm{L}$ ), in the population where weaning failed, it was 114.8 breaths $/ \mathrm{min} / \mathrm{L}(\mathrm{SD}=69.2 ;$ range $47.5-450.0 \mathrm{breaths} / \mathrm{min} / \mathrm{L}$ ). By univariate logistic regression analysis, younger age $(p<0.007)$, female gender $(p<0.001)$, decreased duration of MV $(p<0.023)$, respiratory rate $(p<0.001)$ and $\mathrm{RSBI}(\mathrm{p}<0.001)$, increased tidal volume/ideal body weight $(p<0.001)$ and minute ventilation $(p<0.01)$ were found to be factors that significantly predict successful weaning. By multivariate analysis, increased tidal volume/ /ideal body weight $(p<0.007)$ and decreased RSBI $(p<0.046)$ were found to be independent predictors of successful weaning $\left(\mathrm{p}<0.001 ; \mathrm{R}^{2}\right.$ Nagelkerke $\left.=0.90\right)$.

Conclusions: Factors independently predicting successful weaning in patients requiring extreme PMV included increased tidal volume/ideal body weight and decreased RSBI.
\end{abstract}

Key words: mechanical ventilation, respiratory mechanics, mechanical ventilator weaning, respiratory rate, tidal volume

Adv Respir Med. 2020; 88: 477-484

\section{Introduction}

The timing of weaning from mechanical ventilation should be carefully considered. To initiate the process of weaning, patients should be able to support their own ventilation and oxygenation, and this facility should be assessed continuously. Failed trials of discontinuation of mechanical ventilation may precipitate respiratory muscle injury, and, ultimately, prolong the duration of mechanical ventilation. Moreover, failed trials of extubation have been associated with prolonged hospital stay and excess hospital mortality [1].

One of the best studied and most commonly used weaning predictors over the last three decades, is rapid shallow breathing index (RSBI) - see Table 1. It is defined as the ratio of respiratory rate to tidal volume $\left(\mathrm{f} / \mathrm{V}_{\mathrm{T}}\right)$. It was described in a prospective cohort study of mechanically ventilated patients which found that a RSBI $>105$ breaths/min/L was associated with weaning failure, while a RSBI $<105$ breaths/min/L predicted weaning success with a sensitivity, specificity,

Address for correspondence: Kisil Igor, Chronic Mechanical Ventilation Department, Bayit Balev Geriatric and Rehabilitation Center, Maccabi Health Services, Bat Yam, Israel; e-mail: igork958@gmail.com

DOI: 10.5603/ARM.a2020.0151

Received: 11.03.2020

Copyright (C) 2020 PTChP

ISSN 2451-4934 
Table 1. Summary of studies with predictive measures of successful weaning by rapid shallow breathing index (RSBI), for adults admitted in facilities for long-term care only

\begin{tabular}{|c|c|c|c|c|c|c|c|c|c|}
\hline Study & $\begin{array}{c}\text { Adults } \\
\text { admitted in }\end{array}$ & $\mathbf{N}$ & $\begin{array}{l}\text { Age, mean } \\
\text { years [SD] }\end{array}$ & $\begin{array}{c}\text { Gender } \\
\text { - males, } \\
{[\%]}\end{array}$ & $\begin{array}{c}\text { COPD } \\
{[\%]}\end{array}$ & $\begin{array}{l}\text { MV } \\
\text { prior to weaning, } \\
\text { days }\end{array}$ & $\begin{array}{c}\text { RSBI } \\
\text { [breath/ } \\
\text { /min/L] }\end{array}$ & $\begin{array}{l}\text { Weaning pro- } \\
\text { cess: success } \\
\text { and duration }\end{array}$ & $\begin{array}{l}\text { Logistic } \\
\text { regression }\end{array}$ \\
\hline $\begin{array}{l}\text { Gluc, Corgian } \\
1996 \text { [3] }\end{array}$ & LTVF & 38 & $\begin{array}{c}67.4 \\
(14.9)\end{array}$ & na & 58.0 & $\begin{array}{c}\text { Mean }=23.9 \\
S D=8.9\end{array}$ & na & 1 & na \\
\hline $\begin{array}{l}\text { Chao, } \\
\text { Scheinhorn } \\
2007[4]\end{array}$ & LTVF & 191 & $\begin{array}{c}70.2 \\
(13.0)\end{array}$ & 50.5 & na & $\begin{array}{c}\text { Median }=29 \\
\text { Range } \\
5-136\end{array}$ & $\leq 97$ & $2, \geq 1 \mathrm{~h}$ & na \\
\hline $\begin{array}{l}\text { Wu et al. } \\
2009 \text { [16] }\end{array}$ & LTVF & 1307 & $\begin{array}{c}73.2 \\
(15.3)\end{array}$ & 54.2 & 20.5 & $\geq 21 d$ & $146.4^{\dagger}$ & $2, \geq 1 \mathrm{~d}$ & $\begin{array}{c}\text { OR } \\
0.99\end{array}$ \\
\hline $\begin{array}{l}\text { Verceles et al. } \\
2012 \text { [5] }\end{array}$ & LTAC & 52 & $\begin{array}{c}57.9 \\
(15.7)\end{array}$ & 44.2 & 11.5 & $\geq 21 \mathrm{~d}$ & $\leq 105$ & $2, \geq 2 \mathrm{~d}$ & \# \\
\hline $\begin{array}{l}\text { Dermot Frengley } \\
\text { et al. } 2014 \text { [7] }\end{array}$ & LTAC & 540 & $\begin{array}{l}79.2 \\
(8.1)\end{array}$ & 43.0 & 19.4 & $\begin{array}{c}\text { Median }=39 \\
\text { Range } \\
\text { 26-57 }\end{array}$ & $<105$ & $2, \geq 28 d$ & $\begin{array}{c}\mathrm{aOR} \\
0.99^{* *}\end{array}$ \\
\hline Current study & LTVF & 150 & $\begin{array}{c}76.5 \\
(13.5)\end{array}$ & 40.0 & 8.7 & $\begin{array}{c}\text { Median }=84.5 \\
\text { Range } \\
25-1624\end{array}$ & $41.9^{\dagger}$ & $\begin{array}{r}2 \\
\geq 7 \mathrm{~d}\end{array}$ & $\begin{array}{c}\mathrm{aOR} \\
0.83^{*}\end{array}$ \\
\hline
\end{tabular}

Success in weaning process: ${ }^{2}$ Successful extubation; ${ }^{2}$ Trial of unassisted breathing followed by extubation; ${ }^{*}$ no association; ${ }^{\dagger}$ of success population; ${ }^{*} p<0.05 ;{ }^{* *} p$ $<0.001$. aOR — (adjusted) odds ratio for the likelihood of being successfully weaned; MV — mechanical ventilation; na — not available; LTVF — long-term ventilator facility; LTAC — long-term acute care

positive predictive value and negative predictive value of $97 \%, 64 \%, 78 \%, 95 \%$, respectively [2].

Despite relatively low specificity, RSBI is appropriate for most medical-surgical intensive care patients, but there are no specific and accurate criteria for objective parameters to look for when considering withdrawal, that generalize to all patients [1].

In recent studies, the predictive power of commonly known values of RSBI $(<100$ or $<105$ breaths/min/L) and more than 50 other known weaning measures (vital capacity, maximal inspiratory pressure, expired volume per minute, tidal volume, positive end-expiratory pressure, etc.) has been very poor [1]. The discrepancy in results between the original study [2] and more recent ones may be due to several factors, among them, differences in patient population (intensive care patients, patients requiring PMV [3-5] pediatric [6] or elderly patients [7] etc.), methodology of the weaning process, the absence of objective criteria to determine the tolerance for a trial of discontinuation or extubation [1], the lack of objective criteria to clearly define weaning outcomes [8] and variation in definition of PMV [9] — see Table 1.

The prevalence rate of patients meeting the definition of PMV ( $>21$ days) will likely continue to increase [8]. The value of classic respiratory parameters as weaning predictors in PMV has not been demonstrated [1, 10]. Moreover, few studies have assessed the efficacy of the RSBI in predicting successful weaning in this chronic population $[4,5]-$ see Table 1 . Therefore, the nontraditional values of RSBI (other than $<100$ or $<105$ breaths/min/L) could be important in determining the weanability of patients who have been mechanically ventilated for prolonged periods of time. The aim of this study is to determine the usefulness of RSBI and other potential predictors of successful weaning in patients requiring extremely prolonged mechanical ventilation.

\section{Material and methods}

This is a retrospective study in a 29-bed long-term ventilator facility (LTVF) that is a part of a 282-bed Bayit Balev Geriatric and Rehabilitation community teaching Center (managed by the Maccabi Health care services group) in Bat Yam. This center serves as a tertiary referral center for patients in the central region of Israel. The study was approved by the Institutional Review BoardIRB (IRB approval number 14/2013). Since patient care was not influenced by this study, the IRB did not require informed consent.

\section{Subjects}

All study subjects had undergone tracheostomy and were ventilator dependent for $\geq 21$ consecutive days, for $\geq 6$ hours per day, before admission to our LTVF (during the period between January 
$1^{\text {st }}, 2012$ and December $\left.31^{\text {st }}, 2016\right)$, consistent with the National Association for Medical Direction of Respiratory Care's criteria for PMV [8].

For all of the study subjects before the admission to our LTVF, at least three previous weaning attempts, within at least a week, had failed, they were with tracheostomy, hemodynamically stable, with no need for intensive care, after at least 30 days of stay in general hospital, consistent with the Israeli Ministry of Health definition of patients on PMV [11].

All of the subjects were being supported with one of the following mechanical ventilators: the 740 Ventilator System (Covidien Puritan Bennet, Galway, Ireland); Vela (CareFusion, Viasys); Hamilton - C1, C2 \& Raphael (Hamilton Medical AG, Bonaduz / Switzerland). At baseline, one of the following modes of ventilator support were employed: Volume control intermittent mandatory ventilation (VC-IMV), 135 subjects; Continuous spontaneous ventilation (CSV) + pressure support, 10 subjects; Volume control continuous mandatory ventilation (VC-CMV), 2 subjects; Other modes, 4 subjects.

All the subjects were ready to undergo a weaning process based on the following criteria:

1. Stable hemodynamics without the need for vasoactive or intravenous sedative agents [12-16];

2. Core temperature $<38^{\circ} \mathrm{C}[10,12,13,15,16]$;

3. Absence of acute psychiatric and/or acute neurological disorders [3];

4. Absence of catabolic state: a) severe decubitus; b) serum albumin $>2.4 \mathrm{~g} / \mathrm{dL}$ [3]; c) hemoglobin $\geq 8 \mathrm{~g} / \mathrm{dL}[3,10,13]$;

5. Adequate gas exchange, due to the fraction of inspired oxygen $\left(\mathrm{FiO}_{2}\right) \leq 0.4[15,16]$ with a positive end-expiratory pressure (PEEP) of less or equal than $5 \mathrm{cmH}_{2} \mathrm{O}[15,17]$;

6. Adequate serum electrolyte exchange [3];

7. Being conscious and cooperative [12, 13];

8. In case of chronic obstructive pulmonary disease (COPD) - during the remission phase only;

9. In case of bulbar involvement (multiple sclerosis, Guillain-Barre syndrome, post cerebrovascular accident-CVA, etc.) - appropriate neurological treatment has been given in medical centers before admitting to LTVF. These patients received multidisciplinary treatment (language therapist, physiotherapist and occupational therapist) in order to care for swallowing problems.

The exclusion criteria were the following:

1. Obstructive sleep apnea, apnea due to impaired respiratory drive, apnea due to hyper- ventilation and anxiety before the weaning process;

2. All kinds of hypoventilation before the weaning process (such as due to morbid obesity, etc.). In case of successful treating of these conditions, the eligible subjects have been included in the weaning trail;

3. Abnormal blood gas analysis.

\section{Data collection and measurements}

Medical records were retrospectively reviewed. Recorded data included demographic and clinical features. Pressure support and $\mathrm{FiO}_{2}$ were assessed at baseline.

The other pulmonary mechanics measures (Table 2) were assessed during spontaneous breathing trial. The trial of spontaneous breathing has been continued for 20 minutes approximately on continuous positive airway pressure mode (pressure support 0). During the trial of spontaneous breathing tidal volume, respiratory rate and minute ventilation have been measured.

The ideal body weight (IBW) was calculated using the Stewart equation, based on patient's height and body mass index [18]. In bed-ridden subjects the height was calculated from the value of patient's knee height [19].

\section{Interventions/weaning process}

The weaning protocol was a basis for the gradual removal of ventilator support for all subjects:

1. Disconnection of the patient from the ventilator was carried out in the morning while sitting or lying, after essential parameters were measured and deep suction was performed;

2. The disconnection was carried out while being monitored, after saturation, a few breaths and hemodynamic measurement;

3. The level of end tidal carbon dioxide $\left(\mathrm{etCO}_{2}\right)$ was monitored by capnography;

4. In cases where etCO $\mathrm{C}_{2}$ could not be measured, the $\mathrm{CO}_{2}$ level was measured by means of a blood test for gasses;

5. Each time, when the patient was disconnected from the ventilator, the cannula balloon was deflated;

6. Supplemental $\mathrm{O}_{2}$ was supplied to keep arterial saturations $\geq 90 \%$;

7. In cases of excessive secretion and ineffective coughing, suction was performed as required until the patient learnt to cough effectively;

8. If, during the removal of the ventilator, the patient was able to maintain hemodynamic 
Table 2. The demographics and clinical features of the patient population $(n=150)$

\begin{tabular}{|c|c|c|c|}
\hline Characteristics & $\begin{array}{c}\text { Successfully } \\
\text { weaned }(n=60)\end{array}$ & $\begin{array}{c}\text { Failed } \\
\text { weaning }(n=90)\end{array}$ & P-value \\
\hline Age, median years (IQR) & $\begin{array}{c}76.0 \\
(64.0-82.8)\end{array}$ & $\begin{array}{c}82.5 \\
(74.5-88.0)\end{array}$ & 0.02 \\
\hline Gender — males, n [\%] & $35(58.3)$ & $25(27.8)$ & 0.001 \\
\hline Cause of PMV, n [\%] & & & 0.002 \\
\hline Acute lung disease & $33(70.2)$ & $14(29.8)$ & 0.08 \\
\hline Chronic lung disease & $6(46.2)$ & $7(53.8)$ & 0.29 \\
\hline Neurologic disease & $36(59.0)$ & $25(41.0)$ & 0.84 \\
\hline Cardiac disease & $15(68.2)$ & $7(31.8)$ & 0.40 \\
\hline Miscellaneous & $0(0.0)$ & $7(100.0)$ & 0.001 \\
\hline $\begin{array}{l}\text { Time from intubation to tracheostomy, } \\
\text { median days (IQR) }\end{array}$ & $\begin{array}{c}19.5 \\
(13.2-27.8)\end{array}$ & $\begin{array}{c}23.0 \\
(16.0-33.0)\end{array}$ & 0.07 \\
\hline $\begin{array}{l}\text { Time from tracheostomy to admission in LTVF, } \\
\text { median days (IQR) }\end{array}$ & $\begin{array}{c}19.0 \\
(12.5-39.0)\end{array}$ & $\begin{array}{c}17.0 \\
(10.0-37.8)\end{array}$ & 0.49 \\
\hline Duration of MV, median days (IQR) & $\begin{array}{c}74.5 \\
(52.5-126.2)\end{array}$ & $\begin{array}{c}95.0 \\
(57.5-251.5)\end{array}$ & 0.014 \\
\hline \multicolumn{4}{|l|}{ Baseline pulmonary functions } \\
\hline $\mathrm{FiO}_{2}$, median (IQR) & $\begin{array}{c}40.0 \\
(40.0-40.0)\end{array}$ & $\begin{array}{c}40.0 \\
(40.0-40.0)\end{array}$ & 0.43 \\
\hline $\begin{array}{l}\text { Pressure support, } \\
\text { median } \mathrm{cmH}_{2} \mathrm{O} \text { (IQR) }\end{array}$ & $\begin{array}{c}12.0 \\
(12.0-15.0)\end{array}$ & $\begin{array}{c}14 \\
(12.0-16.0)\end{array}$ & 0.015 \\
\hline \multicolumn{4}{|c|}{ Pulmonary mechanics at spontaneous breathing trial } \\
\hline $\begin{array}{l}\mathrm{f}, \\
\text { median breaths/min (IQR) }\end{array}$ & $\begin{array}{c}18.0 \\
(16.0-20.8)\end{array}$ & $\begin{array}{c}28.0 \\
(21.8-32.0)\end{array}$ & 0.001 \\
\hline $\begin{array}{l}\mathrm{V}_{\mathrm{T}} / \mathrm{IBW}, \\
\text { median } \mathrm{mL} / \mathrm{kg} \text { (IOR) }\end{array}$ & $\begin{array}{c}6.9 \\
(6.3-8.1)\end{array}$ & $\begin{array}{c}4.6 \\
(3.8-5.5)\end{array}$ & 0.001 \\
\hline $\begin{array}{l}\text { Minute ventilation, } \\
\text { median L/min (IOR) }\end{array}$ & $\begin{array}{c}8.2 \\
(7.0-9.8)\end{array}$ & $\begin{array}{c}7.1 \\
(5.7-8.6)\end{array}$ & 0.001 \\
\hline $\begin{array}{l}\text { RSBI, } \\
\text { median breaths/min/L (IQR) }\end{array}$ & $\begin{array}{c}41.3 \\
(35.1-49.4)\end{array}$ & $\begin{array}{c}93.6 \\
(68.4-133.7)\end{array}$ & 0.001 \\
\hline
\end{tabular}

$\mathrm{FiO}_{2}$ — fraction of inspired oxygen; IBT — ideal body weight; IQR — interquartile range; MV — mechanical ventilation; LTVF — long-term ventilator facility; PMV — prolonged mechanical ventilation; $\mathrm{RSBI}$ — rapid shallow breathing index; $\mathrm{V}_{\mathrm{T}}$ — tidal volume

stability ( $>90 \mathrm{~mm}$ Hg systolic blood pressure, heart rate $<110$ per min) and correct levels of etCO $\mathrm{C}_{2}$ and saturation, the period of disconnection was extended by 1-2 hours every few days, according the physician's judgement (avoidance of psychomotor agitation, somnolence, nonadherence to treatment regimen, and the absence of $\mathrm{CO}_{2}$ accumulation/elevation). The patient was monitored as described above and was closely observed by a nurse;

9. During the weaning process, the subjects received adequate pharmacological treatment, respiratory physiotherapy, humidified inspiratory gas and appropriate staff attention;

10. In cases where there was a worsening of the patient's condition, the disconnection was immediately terminated;
11. Discussion of the status of the weaning process and evaluation of the patient's condition was held weekly by a multidisciplinary team and the conclusions were entered into the patient's chart;

12. Even after the disconnection was complete, the patient remained in the unit for at least a week for follow-up before being transferred to another department. He was then given routine monitoring and was located near the nurses' station for lung monitoring;

\section{Weaning outcome measures}

Successful weaning has been defined according to the National Association for Medical Direction of Respiratory Care Consensus Conference 
Guidelines [8]. Subjects were considered weaned if they were independent from mechanical ventilation for 7 consecutive days. A weaning process was defined as the period of 7 days that a patient was considered as actively weaning by respiratory staff and has been classed as failed because at least one of the following criteria:

1. Psychomotor agitation / change in mental status [7, 20];

2. New-onset tachypnea ( $\mathrm{f}>35$ breaths/min) $[4,15,17,21]$;

3. Oxygen saturation (decrease $<90 \%$, despite supplemental oxygen with $\mathrm{FiO}_{2} 60 \%$ ) $[4,7,15]$;

4. Increasing $\mathrm{PetCO}_{2}$ during capnography or increasing $\mathrm{PaCO}_{2}$ in arterial blood more than $50 \mathrm{~mm} \mathrm{Hg}$ with clinical signs, sleeplessness or $\mathrm{CO}_{2}$ narcosis [22]. Hypercapnia (arterial $\mathrm{CO}_{2}>50 \mathrm{~mm} \mathrm{Hg}$ ) without symptoms was not considered as weaning failure. Hypoventilation during sleep was excluded;

5. Hypotension (decrease of $<90 \mathrm{~mm}$ Hg systolic) $[2,7,15,20]$;

6. Evidence of increasing respiratory effort (accessory respiratory muscle involvement, diaphoresis, agitation etc.) $[2,4,7,12,13$, $15,17,20,21]$.

Subjects were considered "not weaned" if they required continuous mechanical ventilation, were transferred to an acute care facility, or died during the study period [16].

\section{Statistical analysis}

Data were analyzed using the Statistical Package for Social Sciences version 20.0 for Windows (SPSS, An IBM Company, version 20). Continuous data are expressed as median with range/interquartile range (IQR) or mean with Standard Deviation (SD), while categorical data are expressed as frequencies and percentage unless otherwise specified. Demographic and clinical characteristics were compared using the Mann-Whitney U test or Chi-square test, as appropriate.

Univariate and multivariate (while controlling for confounding factors) logistic regression analysis with odds ratio (OR) and 95\% confidence interval (95\% CI) was performed to determine the factors predictive of successful weaning. A model to predict successful weaning was then constructed using these factors. A p-value $<0.05$ was considered statistically significant.

\section{Results}

\section{Patient population}

During the study period, there were 211 subjects in our LTVF. After excluding those not eligible for inclusion, 150 subjects were included in this study. Out of them, $60(40.0 \%)$ were males. The mean age of the study population was 76.5 years $(S D=13.6$; range $22.0-96.0$ years). The subjects were on MV for a mean period of 170.1 days $(\mathrm{SD}=237.6$; range 25.0-1624.0 days; IQR 54.0-158.0 days).

Out of the study population, 148 (98.7\%) were ventilator dependent for 24 hours per day and $2(1.3 \%)$ were ventilator dependent for 12 hours per day. All subjects required oxygen therapy.

The causes of PMV [16] were as follows (see Table 2):

1. Acute lung disease $(n=47)$ : pneumonia $(n=$ 16), acute respiratory distress syndrome $(\mathrm{n}=$ 4 ), aspiration pneumonia ( $\mathrm{n}=3$ ), pulmonary embolism $(n=2)$, hemothorax $(n=1)$, lung cancer $(\mathrm{n}=1)$;

2. Chronic lung disease - COPD $(n=13)$;

3. Neurologic disease $(n=61)$ : post CVA $(n=$ $37)$, anoxic brain damage $(n=9)$, traumatic intracranial hemorrhage $(n=5)$, vocal cold paresis $(\mathrm{n}=2)$, Guillain-Barre syndrome (n $=2)$, Parkinson disease $(n=2)$, multiple sclerosis $(\mathrm{n}=1)$, muscular dystrophy $(\mathrm{n}=1)$, spinal cord injury $(n=1)$, Creutzfeldt-Jakob disease $(n=1)$;

4. Cardiac disease $(n=22)$ : congestive heart failure $(n=20)$, cardiac arrest $(n=2)$;

5. Miscellaneous $(n=7)$ : sepsis $(n=6)$, postoperative $(n=1)$.

Out of the study population, 60 (40.0\%) became ventilator independent, without non-invasive support or temporal ventilation, and were discharged. In 30 (50.0\%) of these subjects, tracheostomy was removed. Only 11 (18.3\%) of them were oxygen dependent. The remaining 90 subjects $(60.0 \%)$ were ventilator dependent. Additional patient characteristics, demographics, physiological and clinical variables are depicted in Table 2.

The subjects were grouped with respect to weaning status (successful or failed), and comparisons were made. In the successfully weaned sub-population, there were more males ( $\mathrm{p}<$ $0.001)$, the subjects were younger $(p<0.02)$, and they were mechanically ventilated for a shorter 
period of time $(\mathrm{p}<0.014)$. $\mathrm{V}_{\mathrm{T}} / \mathrm{IBW}(\mathrm{p}<0.001)$ and minute ventilation $(\mathrm{p}<0.001)$ were all significantly higher in the successfully weaned group.

The following were all significantly lower in the successfully weaned group: $f(p<0.001)$, pressure support ( $p<0.015)$, RSBI $(p<0.001)$. The mean RSBI in the successfully weaned population was 41.9 breaths $/ \mathrm{min} / \mathrm{L}(\mathrm{SD}=12.3$; range 13.0-80.4 breaths $/ \mathrm{min} / \mathrm{L}$ ), while in the failed weaned population 114.8 breaths $/ \mathrm{min} / \mathrm{L}(\mathrm{SD}=$ 69.2 ; range $47.5-450.0$ breaths $/ \mathrm{min} / \mathrm{L}$ ).

No deaths occurred during the study period.

\section{Predictive factors of successful weaning}

\section{Univariate logistic regression analysis}

The results of univariate logistic regression analysis are shown in Table 3 . Younger age ( $\mathrm{p}<$ 0.007), female gender ( $<<0.001)$, decreased duration of MV ( $p<0.023), f(p<0.001)$ and RSBI $(\mathrm{p}<0.001)$, increased $\mathrm{V}_{\mathrm{T}} / \mathrm{IBW}(\mathrm{p}<0.001)$ and minute ventilation $(\mathrm{p}<0.001)$ were found to be factors that significantly predict the successful weaning.

\section{Multivariate logistic regression analysis}

The results of multivariate logistic regression analysis are presented in Table 4. Variables with significant differences between outcome groups were chosen. After controlling for confounding factors, increased $\mathrm{V}_{\mathrm{T}} / \mathrm{IBW}(\mathrm{p}<0.007)$ and RSBI ( $\mathrm{p}$ $<0.046$ ) were found to be independent predictors of successful weaning $\left(\mathrm{X}^{2}=164.5 ; \mathrm{df}=7 ; \mathrm{p}<\right.$ 0.001; -2 Log Likelihood $=37.3 ; \mathrm{R}^{2}$ Nagelkerke $=0.90)$.

\section{Discussion}

The current study focused on the investigation of the efficiency of using predictors of successful weaning among patients after PMV. This study was one of the few that investigated the success of weaning of patients who had been ventilated for a very long time (up to nearly 4.5 years).

The findings of the current study showed that low RSBI values and a high $\mathrm{V}_{\mathrm{T}} / \mathrm{IW}$ ratio were independent predictive factors of the success of weaning among this population of patients. With the increase of one unit of RSBI, the chance of successful weaning raised by 0.83 , in other words, decreased. As the $V_{\mathrm{T}} / \mathrm{IW}$ ratio grew by one unit, the chance of successful weaning increased by 6.42. The predictive model of successful weaning in the current study (as shown in Table 4)
Table 3. Summary of univariate analysis revealing the possible factors associated with successful weaning from extreme PMV ( $N=150)$

\begin{tabular}{lccc}
\hline Characteristics & OR & 95\%Cl & P-value \\
\hline Age & 0.96 & $0.94-0.99$ & 0.007 \\
Gender - females vs males & 0.28 & $0.14-0.55$ & 0.001 \\
Duration of MV & 0.997 & $0.995-0.999$ & 0.023 \\
$\mathrm{f}$ & 0.74 & $0.67-0.82$ & 0.001 \\
$\mathrm{~V}_{\mathrm{T}} / \mathrm{IBW}$ & 9.99 & $4.49-22.22$ & 0.001 \\
Minute ventilation & 1.27 & $1.10-1.48$ & 0.001 \\
Pressure support & 0.92 & $0.84-1.01$ & 0.074 \\
RSBI & 0.83 & $0.77-0.89$ & 0.001 \\
\hline
\end{tabular}

IBW — ideal body weight; MV — mechanical ventilation; PMV — prolonged mechanical ventilation; RSBI — rapid shallow breathing index; VT — tidal volume

Table 4. Summary of multivariate analysis revealing the possible factors associated with successful weaning from extreme PMV (N = 150)

\begin{tabular}{lccc}
\hline Characteristics & OR & 95\%Cl & P-value \\
\hline Age & 1.01 & $0.93-1.09$ & 0.89 \\
Gender - females vs males & 1.19 & $0.14-9.81$ & 0.87 \\
Duration of MV & 0.99 & $0.99-1.00$ & 0.23 \\
$\mathrm{f}$ & 1.02 & $0.43-2.42$ & 0.97 \\
$\mathrm{~V}_{\mathrm{T}} / \mathrm{IBW}$ & 6.42 & $1.67-24.69$ & 0.007 \\
Minute ventilation & 0.89 & $0.27-2.87$ & 0.84 \\
RSBI & 0.83 & $0.69-0.99$ & 0.046 \\
\hline
\end{tabular}

IBW — ideal body weight; MV — mechanical ventilation; PMV — prolonged mechanical ventilation; RSBI — rapid shallow breathing index; VT — tidal volume

accounts for $90 \%$ of the variance of success in weaning from PMV. In other words, the variables that were not studied only accounted for $10 \%$ of the variance of success in weaning from PMV. Among the additional advantages of the study is the absence of mortality.

As has been found in previous studies [2326], including among patients after PMV [27], in the current study, a decreased RSBI value has been established as an independent predictive factor of success in weaning. The OR of RSBI as a predictive factor in the current study was 0.83. This means that it has been found in the range of OR of RSBI as an independent predictive factor in previous studies: between 0.64 [26] and 0.99 [16, 23, 24, 27, 28].

In preceding studies, RSBI values lower than 50 breaths/min/L were found [13, 17, 20, $23,25,28,29]$. In our paper, the average RSBI among patients with successful weaning was 
41.9 breaths/min/L. This was one of the lowest values shown in recently published studies, although among intensive care patients. The possible explanation for that may lie in the difference between the study populations: the patients in the acute phase in the intensive care unit (ICU) as opposed to chronic patients in the LTVF.

Until now, no empirical evidence has been found of studies investigating the impact of the $\mathrm{V}_{\mathrm{T}}$ /IBW ratio on the success in weaning from PMV. That said, the recommended values of the $\mathrm{V}_{\mathrm{T}} / \mathrm{IBW}$ ratio in cases of lung-protective mechanical ventilation in patients with severe lung disease, such as ARDS, was in the range of between 4 and $8 \mathrm{~mL} / \mathrm{kg}$ [30]. The average $\mathrm{V}_{\mathrm{T}} / \mathrm{IW}$ ratio in the population with successful weaning in the current study was within this range. From this it can be concluded that there is a need for further investigation of predictive factors of success in weaning after PMV.

Among the possible explanations for the relatively low rate of success in weaning is the advanced age of the study population, which was one of the oldest when compared to those in previous studies $[2,4,7,10,12,13,15,16$, 20, 21]. Only Krieger et al. [7] showed results of weaning in an older population, with a mean age of 79.6 years. An additional explanation may lie in the extremely long period of mechanical ventilation that these patients experienced and medical comorbidities.

\section{Limitations}

Firstly, this was a retrospective analysis of patients transferred to a single unit over a 5-year period. Secondly, the unit was hospital-based, but not community-based. Thirdly, several variables, such as chronic comorbidity or functioning level before the PMV, were not analyzed in this study. Middle-term and/or long-term outcomes, such as all-cause mortality, may be more meaningful and helpful in providing patients and significant others with realistic outcome expectations.

\section{Conclusions}

Factors independently predicting successful weaning in patients requiring extreme PMV included increased tidal volume/ideal body weight and decreased RSBI. The weaning process, also very prolonged, still falls in the gap between art and science. Additional clinical research with rigorous selection of subjects and a standard weaning protocol, along with long-term outcome monitoring after PMV, is needed. The prevalence of patients requiring PMV is steadily increasing and this demands adequate funding and promotion of this kind of research.

\section{Author contributions}

YL — study design, review of manuscript; IK — literature search, data collection, study design, manuscript preparation, and takes responsibility for the integrity of the data and the accuracy of the data analysis, including and especially any adverse effects; AP — data collection; VS — data collection; YG - data collection; AN — data collection; YG - literature search, statistical analysis of data, writing of the manuscript and review.

\section{Conflict of interest}

None declared.

\section{References:}

1. Meade M, Guyatt G, Cook D, et al. Predicting success in weaning from mechanical ventilation. Chest. 2001; 120(6 Suppl): 400S-424S, doi: 10.1378/chest.120.6_suppl.400s, indexed in Pubmed: 11742961.

2. Yang KL, Tobin MJ. A prospective study of indexes predicting the outcome of trials of weaning from mechanical ventilation. N Engl J Med. 1991; 324(21): 1445-1450, doi: 10.1056/ NEJM199105233242101, indexed in Pubmed: 2023603.

3. Gluck EH. Predicting eventual success or failure to wean in patients receiving long-term mechanical ventilation. Chest. 1996; 110(4): 1018-1024, doi: 10.1378/chest.110.4.1018, indexed in Pubmed: $\underline{874263}$.

4. Chao DC, Scheinhorn DJ. Determining the best threshold of rapid shallow breathing index in a therapist-implemented patient-specific weaning protocol. Respir Care. 2007; 52(2): 159-65.

5. Verceles AC, Diaz-Abad M, Geiger-Brown J, et al. Testing the prognostic value of the rapid shallow breathing index in predicting successful weaning in patients requiring prolonged mechanical ventilation. Heart Lung. 2012; 41(6): 546-552, doi: 10.1016/j.hrtlng.2012.06.003, indexed in Pubmed: 22770598.

6. Baumeister BL, el-Khatib M, Smith PG, et al. Evaluation of predictors of weaning from mechanical ventilation in pediatric patients. Pediatr Pulmonol. 1997; 24(5): 344-352, doi: $10.1002 /$ (sici)1099-0496(199711)24:5<344::aid-ppul7>3.0.co;2-i, indexed in Pubmed: $\underline{9407568}$.

7. Krieger BP, Isber J, Breitenbucher A, et al. Serial measurements of the rapid-shallow-breathing index as a predictor of weaning outcome in elderly medical patients. Chest. 1997; 112(4): 1029-1034, doi: 10.1378/chest.112.4.1029, indexed in Pubmed: $\underline{9377913}$.

8. MacIntyre NR, Epstein SK, Carson S, et al. Management of patients requiring prolonged mechanical ventilation: report of a NAMDRC consensus conference. Chest. 2005; 128(6): 39373954, doi: 10.1378/chest.128.6.3937, indexed in Pubmed: 16354866.

9. Rose L, McGinlay M, Amin R, et al. Variation in definition of prolonged mechanical ventilation. Respir Care. 2017; 62(10): 1324-1332, doi: 10.4187/respcare.05485, indexed in Pubmed: 28611229.

10. Vallverdú I, Calaf N, Subirana M, et al. Clinical characteristics, respiratory functional parameters, and outcome of a two-hour T-piece trial in patients weaning from mechanical ventilation. Am J Respir Crit Care Med. 1998; 158(6): 1855-1862, doi: 10.1164/ajrccm.158.6.9712135, indexed in Pubmed: 9847278. 
11. Ministry of Health in Israel. Licensing and activation of longterm ventilator facility. Circular number 48/2008, folder number 200/0/3. 2008.

12. Gandia F, Blanco J. Evaluation of indexes predicting the outcome of ventilator weaning and value of adding supplemental inspiratory load. Intensive Care Med. 1992; 18(6): 327-333, doi: 10.1007/BF01694360, indexed in Pubmed: 1469159.

13. Capdevila XJ, Perrigault PF, Perey PJ, et al. Occlusion pressure and its ratio to maximum inspiratory pressure are useful predictors for successful extubation following T-piece weaning trial. Chest. 1995; 108(2): 482-489, doi: 10.1378/chest.108.2.482, indexed in Pubmed: 7634888.

14. Leitch EA, Moran JL, Grealy B. Weaning and extubation in the intensive care unit. Clinical or index-driven approach? Intensive Care Med. 1996; 22(8): 752-759, doi: 10.1007/ BF01709517, indexed in Pubmed: 8880243.

15. Kuo PH, Wu HD, Lu BY, et al. Predictive value of rapid shallow breathing index measured at initiation and termination of a 2-hour spontaneous breathing trial for weaning outcome in ICU patients. J Formos Med Assoc. 2006; 105(5): 390-398, doi: 10.1016/S0929-6646(09)60135-2, indexed in Pubmed: 16638649 .

16. Wu YK, Kao KC, Hsu KH, et al. Predictors of successful weaning from prolonged mechanical ventilation in Taiwan. Respir Med. 2009; 103(8): 1189-1195, doi: 10.1016/i.rmed.2009.02.005, indexed in Pubmed: 19359156.

17. Martinez A, Seymour C, Nam M. Minute ventilation recovery time: a predictor of extubation outcome. Chest. 2003; 123(4): 1214-1221, doi: 10.1378/chest.123.4.1214, indexed in Pubmed: 12684314.

18. Stewart TE, Meade MO, Cook DJ, et al. Evaluation of a ventilation strategy to prevent barotrauma in patients at high risk for acute respiratory distress syndrome. Pressure- and Volume-Limited Ventilation Strategy Group. N Engl J Med. 1998; 338(6): 355-361, doi: 10.1056/NEJM199802053380603, indexed in Pubmed: 9449728.

19. Chumlea WC, Roche AF, Steinbaugh ML. Estimating stature from knee height for persons 60 to 90 years of age. J Am Geriatr Soc. 1985; 33(2): 116-120, doi: 10.1111/j.1532-5415.1985. tb02276.x, indexed in Pubmed: 3968366.

20. Del Rosario N, Sassoon CS, Chetty KG, et al. Breathing pattern during acute respiratory failure and recovery. Eur Respir J.
1997; 10(11): 2560-2565, doi: 10.1183/09031936.97.10112560, indexed in Pubmed: $\underline{9426095}$.

21. Lee KH, Hui KP, Chan TB, et al. Rapid shallow breathing (frequency-tidal volume ratio) did not predict extubation outcome. Chest. 1994; 105(2): 540-543, doi: 10.1378/chest.105.2.540, indexed in Pubmed: 8306759.

22. Boles JM, Bion J, Connors A, et al. Weaning from mechanical ventilation. Eur Respir J. 2007; 29(5): 1033-1056, doi: 10.1183/09031936.00010206, indexed in Pubmed: 17470624.

23. Tu X. [Application of multi-predictors in the ventilator weaning process]. Zhonghua Jie He He Hu Xi Za Zhi. 2004; 27(12): 829-832, indexed in Pubmed: 15730783.

24. Su CL, Chiang LL, Yang SH, et al. Preventive use of noninvasive ventilation after extubation: a prospective, multicenter randomized controlled trial. Respir Care. 2012; 57(2): 204-210, doi: 10.4187/respcare.01141, indexed in Pubmed: 21762554.

25. Bien UD, Souza GF, Campos ES, et al. Maximum inspiratory pressure and rapid shallow breathing index as predictors of successful ventilator weaning. J Phys Ther Sci. 2015; 27(12): 37233727, doi: 10.1589/ipts.27.3723, indexed in Pubmed: 26834339.

26. Lai CC, Chen CM, Chiang SR, et al. Establishing predictors for successfully planned endotracheal extubation. Medicine (Baltimore). 2016; 95(41): e4852, doi: 10.1097/ MD.0000000000004852, indexed in Pubmed: 27741103.

27. Dermot Frengley J, Sansone GR, Shakya K, et al. Prolonged mechanical ventilation in 540 seriously ill older adults: effects of increasing age on clinical outcomes and survival. J Am Geriatr Soc. 2014; 62(1): 1-9, doi: 10.1111/jgs.12597, indexed in Pubmed: 24404850.

28. Frutos-Vivar F, Ferguson ND, Esteban A, et al. Risk factors for extubation failure in patients following a successful spontaneous breathing trial. Chest. 2006; 130(6): 1664-1671, doi: 10.1378/chest.130.6.1664, indexed in Pubmed: 17166980.

29. Seely AJE, Bravi A, Herry C, et al. Do heart and respiratory rate variability improve prediction of extubation outcomes in critically ill patients? Crit Care. 2014; 18(2): R65, doi: 10.1186/ cc13822, indexed in Pubmed: 24713049.

30. Forel JM, Roch A, Marin V, et al. Neuromuscular blocking agents decrease inflammatory response in patients presenting with acute respiratory distress syndrome. Crit Care Med. 2006; 34(11): 2749-2757, doi: 10.1097/01. CCM.0000239435.87433.0D, indexed in Pubmed: 16932229. 